\title{
El Teatre Catalá (1912-1917). Noticias en torno a la crisis del teatro
}

\author{
ÓsCar Fernández Poza
}

(UCM)

\section{El Teatre Català}

Es una de las publicaciones barcelonesas más importantes para el estudio de la historia literaria catalana, en especial para el teatro, junto con otras revistas teatrales de la época, como es el caso de La Escena Catalana, como veremos más adelante.

Esta publicación emprendió su aventura el 29 de febrero de $1912^{1}$ y su último número es del 24 de marzo de $1917,{ }^{2}$ durante este periodo, se podría hablar de dos épocas, pero su división no es debida a cambios estéticos o de contenido, sino a la fusión con otra de las revistas emblemáticas dedicadas al teatro catalán, La Escena Catalana ${ }^{3}$ publicación que tiene una larga existencia. La fusión se produce el segundo año de El Teatre Català, siendo efectiva a partir del número 57, aunque en los dos números anteriores aparecen dos artículos donde se comentan los detalles de la misma. ${ }^{4}$

Comenzó a imprimirse en la Imprenta ARTIS \& Co. (Balmes, 54, Barcelona), posteriormente en la Imprenta d'Art (Provença, 304, Barcelona) y definitivamente se vuelve a imprimir en la imprenta de Avel-lí Artís. Aparecía los jueves, pero desde el número 8 , pasa a divulgarse los sábados, porque:

«Efectivament donada l'extensa informació literària i gràfica que'l nostre periòdic publica del moviment teatral, i coincidint la major part d'estrenes i re-

' Como curiosidad sobre la distribución de los diferentes números de la revista, en Memòries de Josep Rocarol (Barcelona, Hacer editorial, 1999) comenta: «Aquesta publicació es tirava en la impremta que tenia l'Artís (amb dos mes) i el dia de sortir la revista, nosaltres mateixos, a la nit, feiem els paquets per als corresponsals forans, i els portàvem a Correus, així com els de Barcelona els feia un germà de l'Artís que tenia un quiosc a la Rambla i n'era el distribuïdor per a la ciutat», p. 71 .

${ }^{2}$ En nuestra investigación no hemos encontrado ninguna referencia en las publicaciones coetáneas las causas del cierre de El Teatre Català.

3 Para mayor información sobre «La Escena Catalana» ver Història de la premsa catalana de Torrent i Fàbregas, J. y Rafael Tasis, Barcelona, Bruguera, 1966, Vol. I, p. 413 y 545.

4 Véase «Importantíssim als postres llegidors», núm. 55 (15-3-1913), p. 178 y «La fusió de 'LEscena Catalana' i El Teatre Català», núm. 56 (22-3-1913), pp. 188-189. 
presentacions en els dies que precisament acaba de llançar-se el número a la venda, fa que rebem tard les ressenyes i que's retrassi la sortida, lo que es un manifest perjudici pera nosaltres i una explicable contrarietat pera'ls caríssims amics que'ns llegeixen.

Així, a començar des de la venien setmana, EL TEATRE CATALÀ apareixerà els dissabtes, esperant que aquesta decisió serà del gust de tots» ${ }^{5}$.

La administración y redacción de la revista sufrió diversos cambios de ubicación, desde estar instalada «al carrer de la Portaferriça, 17, llibreria de Farrè i Asensio», pasando por la Plaça del Beat Oriol 6 (Barcelona), y definitivamente al Carrer de Boters, 16, 1. . En cuanto a los nombres de los administradores no aparece gran información, sólo encontramos entre las páginas de la publicación dos nombres, Francesc Miralles y Salvador Bonavía.

Tiene un formato de $275 \times 188 \mathrm{~mm}$, cada número está compuesto por dieciséis páginas a dos columnas y cubiertas. Durante un periodo corto de tiempo sufrió una reducción de páginas, esta circunstancia es anunciada en el número 208 , siendo efectiva desde el número siguiente, ${ }^{6}$ y a partir del número 253 se vuelve a 16 planas con las cubiertas incluidas.

La paginación no es coherente, es decir, en el primer año cada uno de los números tiene una numeración independiente. En los otros años es correlativa e independiente del resto. Pero en el quinto año de publicación, tenemos diversos errores de paginación, en el primer número de ese año (núm. 201, 1 de enero de 1916), continúa con la del año anterior, pero en el siguiente número encontramos una nueva, pero ya desde la página 17 , teniendo en cuenta las páginas del primer número del año; y a partir del número 216 sufre una modificación, vuelve a numerarse a partir de la página 135 cuando le correspondería la 185 . Y en el sexto y último año de la publicación, la paginación comienza desde la cubierta y no desde la primera página del número como ocurría hasta este momento.

Los propósitos de El Teatre Català los encontramos publicados por primera vez en LaVeu de Catalunya.' Pero es en el primer número de la revista, en su

5 Núm. 7, 14 d'abril de 1912, p. 23

${ }^{6}$ La principal causa aducida para la eliminación de páginas fue el elevadísimo coste del papel, por su escasez debido a la Gran Guerra. Queda reducido el tamaño a 8 planas de texto y cuatro de cubierta, pero aumentan las páginas destinadas al folletín de 16 a 24.

${ }^{7}$ La Veu de Catalunya, dimecres 21 de febrer de 1912, Any XXII, núm. 4585, p. 6, en la sección dedicada a los teatros:

«Havem escullit el nom d' "El Teatre Català" perque ens ha semblat que ab ell se sintetisava y comprenía tot lo que deu èsser objecte de la nostra devoció.

Pretenem que la nostra revista segui assequible a totes les classes socials sense cap excepció, unint llaços entre artistes y públich, fins a ferse interessant y indispensable a tots els que, per professió o afecte, estàn relacionats ab les coses de teatre. Ens considereríem ben pagats y satisfets si conseguíem fer minvar aqueixa mena de menyspreu o apartament de part del nostre poble de tot lo que a teatre fa referencia, duent al seu convenciment el que un actor es un artista y no un histrió, y que les obres dramàtiques no son pas d'un nivell més baix que'l dels demés genres de literatura.

Setze pàgines luxosament editades del format y paper d'aquest prospecte, ab artístiques y elegants cobertes en color, contenint extensa informació gràfica y literaria de tots els aconteixements 
Crònica - inaugural-, donde se explica los propósitos de ésta de «aspirar a esser un ressò vibrant de la nostra escena, potser no'ns hauriem atrevit a intentarla si no haguessim estat fermament convençuts de que podiem comptar amb la simpatía i adhesió de tots aquells elements afectes al Teatre de Catalunya que amb la seva ajuda havien de completar forçosament la bondat de les nostres intencions...». Y

«...s'hi podran tractar tota mena d'assumptes d'interès general que directa o indirectament se refereixin a les coses i a la gent del nostre art dramàtic, però mai, absolutament mai, tindran aculliment en aquest periòdic aquella mena de campanyes que passen d'opinió a insidia, i d'aquesta a intriga, pera descendir al fons de les baixes passions.

Estem disposat a situar-nos tant lluny de l'elogi desmesurat com de la crítica despietada; tindrem en tots casos la nostra opinió, ben nostra i ben independenta, però en un terme mitg en que's trobin, per un costat les naturals exigencies de l'art escènic, i per l'altre la bona voluntad i entusiasme dels que a sa major honra i gloria hi aporten la florida de les seves iniciatives i la maduresa de les seves obres. Procurarem prodigar més l'elogi que la censura, i quan aquesta's fassi inevitable ho farem de manera que la nostra lleal opinió pugui ser presa com a saludable advertencia i no com a ofensa que fereixi»"

De acuerdo con el libro de P. Vidal, Els singulars anecdòtics (Barcelona, Joaquim Horta, impressor, 1920, p. 125), los fundadores de la publicación son: Francesc Curet, Josep Sanxo Ferrerons, Avel-lí Artís y Ambrosi Carrión. La dirección queda en manos de Francesc Curet.

En palabras del propio Francesc Curet —en su Història del Teatre Català (Barcelona, Aedos, 1967, pp. 612-613), donde nos informa con mayor precisión de los fundadores de la revista y primeros integrantes de la redacción de la revista-:

«A començos del 1912, amb Avelí Artís, Joan Sanxo i Farrerons, Ambrosi Carrion, Josep Rocarol i Pau Audouard, l'excel' lent fotògraf, vam fundar "El Teatre Català"; quan feia poc de la seva publicació se sumaren a la colla Vicenç Caldés i Arús, Ramon Vilaró i Guillemí, Carles Moreno, crític musical, Josep Ferràn Torres, Joan Duran Vila, Josep Pujol i Brull i Daniel Masgoumiery, en qualitat de dibuixant. Més tard s'afegirem, entre altres, Ramon Gatuelles i Ernest Batlle i Rovira, corresponsals a Madrid i París, respectivament, Rafael Bori, els dibuixants Jaume Passarell, Josep Toullot, Lluís Capdevila i Emili Saleta i Llorens»

Y a lo largo de las páginas de la revista podemos observar como van cambiando los miembros de la redacción, como ocurre en el número 56 , con la fu-

que a l'art teatral fassin referencia, y interessants treballs sobre'ls seus variats aspectes, compondràn la revista «El Teatre Català».

\& El Teatre Catalá, Crònica, núm. 1 (29 de febrero de 1912), p. 2. 
sión con La Escena Catalana; se unen a ella: Pompeu Crehuet, Salvador Bonavía, Antoni M. Muntañola, J. Batllibosch y Emili Saleta i Vidal. En el mismo número 149, según Puck ${ }^{9}$ en el artículo «La gent de casa» (pp. 31-32), la Redacción estaría formada en esos momentos por: Francesc Curet, Ramon Vilaró i Guillemí, Josep Ferràn Torras, Carles Moreno, Vicenç Caldés i Arús, Josep Rocarol, Joan Duràn, Ambrosi Carrión, Victorià Johannus y Daniel. En él se definía a cada uno de sus compañeros de redacción, en aquellos momentos.

La estructura de la publicación tiene un formato que se va conformando durante su historia. La portada, ${ }^{10}$ por lo general, es del mismo estilo en todos los números; posee una fotografía de alguna personalidad importante del mundo del teatro de la cual se hable en el número respectivo, o una caricatura de algún personaje o dos tipos de dibujos de Daniel. Sobre estas ilustraciones aparece el título de la publicación. Pero entre los números 97 al 150 hay un cambio: aparece una fotografía, pero ésta, que se encuentra en la página siguiente, aparece a través de una abertura en la parte central de la portada en forma de óvalo, coincidiendo con la fotografía de la primera página de cada número.

En la segunda plana, aparece una de las secciones fijas y seguramente una de las más importantes, la Crònica, que se puede calificar como editorial de la publicación, es decir, en ella se insertan las ideas estéticas y literarias que defiende la redacción. "En las páginas sucesivas aparecen diferentes artículos, poesías y fragmentos de obras teatrales. Pero en su mayoría están ocupadas por secciones fijas que van apareciendo en diferentes momentos de la historia de la publicación. Estas secciones fijas son: Ironíes, Crònica Musical, Teatre Estranger, Teatre Castellà, Teatre Català y Notícies.

La sección Ironíes firmada por Puck pretendía cada semana: «la de trasplantar en aquestes ratlles lo que, passant, passant, me sembli més adequat a la naturalesa de la Revista; sense que això suposi una renuncia al comentari, l'observació, l'elogi o la desalabança, fills d'un criteri propi...». ${ }^{12}$

La Crònica Musical, es la sección donde se recogen todas las informaciones sobre los estrenos musicales acontecidos durante la semana en los diferentes locales y teatros barceloneses dedicados a este arte. En la mayoría de las ocasiones está firmada por Orpheus, seudónimo de Carles Moreno, también encargado de las crónicas musicales en El Poble Català, hasta finales de octubre de 1916.

En las secciones Teatre Estranger, Teatre Castellà y Teatre Català se recogen las informaciones de las diferentes representaciones semanales de obras teatrales en los coliseos catalanes, principalmente de Barcelona, Madrid y las principales ciudades europeas.

${ }^{9}$ Seudónimo de Vicenç Caldés i Arús

10 Josep Rocarol en sus memorias (Memòries de Josep Rocarol Escenògraf. 1882-1961, Barcelona, Hacer editorial, 1999) habla de la revista, ya que es uno de los integrantes de la redacción, y a su vez es el autor de «portada, lletres capitals, culs de llànita, frisos, etc.», p. 71.

"Aunque existe algún ejemplo de intervención en la vida política, como es el caso de Crònica. Per la Mancomunitat catalana, núm. 87 (25 de octubre de 1913).

12 Núm. 19 (6-07-1912), p. 7. 
Y por último, nos remitiremos a los artículos críticos y de creación literaria aparecidos. Tenemos una gran cantidad de estos dos tipos de artículos, que son la otra gran parte del contenido. La temática de los artículos críticos es teatral y se ocupa de las diferentes facetas dentro de este mundo, es decir, desde la problemática de la crisis teatral, ${ }^{13}$ sobre los cómicos, ${ }^{14}$ o sobre la gestión del Ayuntamiento de Barcelona en temas relacionados con el teatro. ${ }^{15}$

\section{II. ¿Está en crisis el teatro catalán?}

Entre los temas que trata a lo largo de su existencia editorial destaca el de la situación del teatro catalán, si se encontraba en crisis o no.$^{16}$ Este asunto ha estado presente largamente en la historia literaria catalana, desde el comienzo de la recuperación literaria de la lengua catalana en la Renaixença hasta nuestros días. Pero en aquel momento la referida cuestión no era exclusiva del teatro catalán, sino también del teatro castellano y mundial.

En la prensa catalana de la época existía un continuo debate sobre si el teatro estaba muerto o no; dentro de esta publicación encontramos numerosos ejemplos. En algunas de las Ironies de Puck, ${ }^{17}$ por ejemplo, se comenta que no hay que utilizar la palabra crisis, porque, cuanto más se la utilice, tanto más se agravará la crisis del teatro catalán, que no es tan real como la quieren presentar otros. En un artículo de Joaquim Civera y Sormani, Injustita,$^{18}$ se comenta que el teatro catalán no está muerto, sino que la muerte es de todo el teatro en general.

En una entrevista que realiza Salvador Bonavía a Ignasi Iglesias, ${ }^{19}$ éste piensa que el teatro no está muerto, sino que se encuentra en reposo, o en un artículo de D. Martí i Julià, La vera crisi, ${ }^{20}$ se comenta que la crisis del teatro catalán no es una crisis como se ha venido comentando, es una crisis evolutiva del teatro regional al teatro nacional.

Josep Rocarol, en sus Memòries ${ }^{21}$ comentando una cena en Arenys en honor de Josep Maria Arnau, señala que Albert Llanas afirmó: «El teatre català no és mort, sinó que fa l'orni».

${ }_{13}$ Véase por ejemplo el artículo de Josep Artís Si en Borràs es quedes!, núm. 64 del 17 de mayo de 1913, pp. 323-324.

14 Véase por ejemplo el artículo de Aroma Els nostres còmics en societats, núm. 91 del 22 de noviembre de 1913, pp. 815-816.

is Véase por ejemplo el artículo de Aroma Ni biblioteques ni museus, núm. 95 del 20 de diciembre de 1913, pp. 875-877.

${ }^{16}$ Otro de los grandes temas que maneja es el de la cuestión de la creación de un Teatro Nacional, tema que se tratará en un futuro artículo.

17 Véase Ironies, núm. 32 (5 d'octubre de 1912), p. 18

18 Núm. 37 (9 de novembre de 1912), pp. 12-13.

19 Véase Els nostres artistes en l'intimitat. Ignasi Iglesias, núm. 62 (3 de maig de 1913), pp. 288-291.

${ }^{20}$ Núm. 149 ( 2 de janer de 1915), pp, 2 y 4.

${ }^{21}$ Op. cit, p. 78 
En la prensa catalana encontramos más ejemplos. En un artículo de Manuel Aragall, «De nostre teatro catalá: consideracions», ${ }^{22}$ aparecido en Lo Teatro Regional, donde se analizan las causas del teatro catalán, comenta que tras la muerte de Frederic Soler, Pitarra, el teatro catalán recibe «una punyalada certera que bé podriam calificar de grave, pero no tant com molts suposan, puig molt abans que la mort ab sa implacable urpada se'n emportés tant prompte aquell geni, lo teatro catalá arrossegaba una vida raquítica y escrofulosa, que tots los olis de fetje de bacallá no haurian bastat per reforsarlo».

Durante la época de El Teatre Català, uno de los críticos teatrales más importantes de esos momentos en el ámbito catalán, Alexandre Plana, desde las páginas de El Poble Catala del día 27 de febrero de 1911, trata el tema de la crisis del teatro en el artículo «Sobre la crisi del Teatre Català» ${ }^{23}$ y se manifestaba en los siguientes términos:

«Jo no he cregut mai en la «crisi» de res. (...) Se parla de crisi del Teatre Català quan han funcionat alhora dos teatres amb companyia catalana, no recordant-se de que en aquells «gloriosos» temps d'en Pitarra si n'hi havia un era perquè no hi havia gairebé altre teatre a Barcelona, mentre que ara en funcionen normalment deu o dotze, i això que, amb la introducció del cinematògraf amb ses condicions d'economia i rapidesa, $s$ 'ha establert una competència ben agra i difícil entre les dues meses d'espectacle» (p. 32)

No cree que exista crisis en el teatro catalán o en el teatro en general, sino que, por el contrario, existen grandes figuras tanto en Europa como en Cataluña. ${ }^{24}$

En otro artículo del mismo autor, "Notes marginals a una conferència de l'Adrià Gual», ${ }^{25}$ también publicado en el diario El Poble Català, —aprovechando la aparición de un folleto de Adrià Gual, Les orientacions, y una conferencia suya tratando el problema del teatro catalán-, dice que no se puede comparar la escena catalana con otras europeas, pues si se compara así sale matemáticamente la crisis del teatro catalán. Destaca que el teatro catalán está encerrado en sí mismo; no recibe influencias del exterior, es un teatro particularista, como ya indicó Alexandre Cortada en el siglo XIX.

\section{Causas de la crisis teatral}

Volviendo a El Teatre Català, vamos a recordar algunas crónicas aparecidas en donde se trata el problema de la crisis del teatro catalán de forma general y de

22 Núm. 248 del 7 de noviembre de 1896, pp. 292-293.

23. Texto extraído del libro de Alexandre Plana Teoria i Crítica del Teatre, edición a cargo de Iolanda Pelegrí, Barcelona, Publicacions de I'Institut del Teatre, Edicions 62, 1976.

${ }^{24}$ Esta afirmación la podemos comprobar en la siguiente cita del mismo artículo: «No hi ha crisi del Teatre Català. (...) si la crisi existeix és, en tot cas, una crisi externa, no pas interna; de funcionament, no pas d'organisme.» (pp. 32-33)

${ }^{25}$ Op. cit. 
sus causas, proponiendo algunas soluciones. Por ejemplo, en la Crònica. Balanç de l'any, ${ }^{26}$ donde se realiza un balance del anterior año teatral catalán, se plantean algunas de las causas de la crisis teatral:

«Massa mal s'hi ha fet en Teatre Català, i just és que'ls aires es purifiquin. Entre mercaders, ineptes i pedants, l'art dramàtic de Catalunya se n'ha vist de totes. D'autors novells no'n pujen; els que estrenen, treuen al públic a empentes. Consti que parlem de l'any passat. Els còmics, dels pocs que'ns resten, fòra algunes comptades, i tant comptades!, excepcions, segueixen la seva: no preocupar-se de res, no estimar res del teatre aon hi menjen o aon hi dejunen, però aon deuen tenir-se afeccions, no estudiar res dels papers, no saber de res $\mathrm{i}$ malparlar de tot. També els comediants catalans treuen al públic a empentes. I el públic és Vox Dei.

Passem per una època de depresió patriòtica; ens aigualim nosaltres mateixos, no vibra en nosaltres aquell esperit que fa moure les grans causes; el teatre es ressent del mal general, i ho demostra a les clares, com la blancor en la llengua i el mal revelen l'estat dolent del ventrell.

Si el patriotisme català no estés en crisi, el nostre teatre no patiría. Si la vergonya patriòtica ens enrojolés el rostre, encara, no els hi sería permès ni a don Enric ni a donya Marguerida, Borràs i Xirgú respectivament, a presentar-se'ns en castellanista, que és pitjor que en castellà. La sanció popular fora justa i implacable.

A manca de Teatre Català oficial i fermament constituit, $s$ 'han obert $i$ tancat a intervals varies temporades més o menys curtes.»

Y en la Crònica. Tants caps, tants barrets, ${ }^{27}$ se analizan las causas de la crisis del teatro catalán en los siguientes términos:

«I. - En els moments actuals no hi ha públic bastant a Barcelona per a donar vida a més d'un teatre català que funcioni diariament. Es clar que amb un sol teatre no és possible donar satisfacció a tots els gustos i tendencies i que'l terme mig acostuma no complaure a tothom, però una mútua transacció en sentit ampli pot donar fermesa als primers passos del teatre convalescent.

II.- El nombre infinit de societats que conresen particularment el teatre català, resten un nombre considerable d'espectadors a la temporada oficial que s'organitzés. Es un problema aquest quasi insoluble.

Més val que'ls aficionats representin obres catalanes que no pas forasteres i cal agraïr la bona voluntat dels que en èpoques de depresió han contribuit a que les representacions catalanes no quedessin del tot esborrades dels cartells, però és induptable que la dispersió i apartament de públic dels grans teatres a on s'hi fa català existeix, sense gran profit per l'art escènic.

26 Núm. 150 (9 de enero de 1915), pp. 33-35.

27 Núm. 203 (15 de gener de 1916), pp. 33-35. 
III.-L'anarquía i la desmoralització artística entre'ls nostres actors, produida per l'inestabilitat del teatre, és un dany que s'ha de remeiar radicalment i amb cauteri.

L'escena catalana no compta amb segones parts; té, per les circumstancies i per la vanitat, una cinquantena de primers actors $i$ actrius nominals amb un parell o tres de realment efectius. Conseguir una companyía homogenia, compacta i disciplinada, és un problema que cal resoldre acudint a tota mena de procediments.

IV.- Les escoles de declamació, nascudes també per generació espontania com els bolets, no conseguiràn cap resultat positiu mentres l'alumne aventatjat no tingui el premi de ser enlairat a la categoría d'actor en exercici constant, com aquella homogenitat i disciplina de que parlèvem, no's conseguirà fins que'l comediant sàpiga que jamai li pot mancar el pà».

O finalmente en la Crònica. Llegeix, amic!, ${ }^{28}$ se alerta sobre el problema de la crisis del teatro catalán, comentando que no es problema de autores, ni de actores, sino de las empresas. Se propone, para intentar salvar la situación, crear un organismo para la defensa del teatro catalán. En la Crònica anteriormente citada se comenta:

«...UN ORGANISME QUE AJUNTI ELS ESFORÇOS, ELS ENTUSIASMES I LA BONA VOLUNTAT DELS QUE SENTEN SIMPATÍA PEL TEATRE CATALÀ, I SIGUI IMPULS, GUIA I FONAMENT D'UN NOU ES. TAT PROPICI A LA CONSOLIDACIÓ DEFINITIVA DEL NOSTRE ART DRAMÀTIC.

No és un falansteri de sabis i de dilettanti lo que volem formar. No és una entitat de professionals lo que anem a constituir. Aspirem a que el públic es faci seva la causa del Teatre Català, i el salvi i el redimeixi.

(...)Volem que per damunt dels reglaments que s'estableixin hi suri una amplia llibertat, que la futura colectivitat d'aimants del Teatre Català sigui un cos compacte i ensinestrat, amb estridencies i apassionaments, però duent el llevat fructífer del que edifica cantant i rient.»

En cuanto a las causas tenemos artículos que tratan de una forma general este tema. Podemos citar el de Ambrosi Carrión, Del nostre teatre i per al nostre teatre ${ }^{29}$ donde el autor pone de manifiesto que los motivos causantes o causas de esta crisis son el público y los actores. El primero por el desinterés por el teatro patrio, ya que en la literatura catalana no faltan autores destacados; y los comediantes, por la emigración de éstos a otras tierras, pudiéndose arreglar los problemas con la Escola catalana d'Art Dramàtic. Añade además el cine como causa del declive del teatro.

En una conferencia de Ramon Vilaró i Guillemí, El teatre català i la crisi patriòtica ${ }^{30}$ realizada en el local del Foment del Teatre Català, se dan algunas

${ }^{28}$ Núm. 123 (4 de juliol de 1914), pp. 434-436.

${ }^{29}$ Núm. 70 (28 de juny de 1913), pp. 419-420.

${ }^{30}$ Núm. 162 (3 d'abril de 1915), pp. 226-227. 
ideas sobre las causas de la crisis, como la falta de patriotismo, las deserciones de los actores, etc., y se proponen soluciones, que pasan por la Mancomunitat, organismo político-administrativo, «regularitzant el séu funcionament, cónstruint l'edifici i creant una escola d'actors que encara no tenim».

Como refleja la anterior cita, existía dentro de la publicación y entre los aficionados del teatro un intento por salvar la escena de la crisis en la que se encontraba inmersa. Por ejemplo, Victorià Benedicto en el artículo Tribuna libre. La crisis del teatre catala,$^{31}$ da una serie de directrices para mejorar el teatro, como respeto al director dentro y fuera de los escenarios, y el papel de las empresas, que «no s'han de casar ni amb un home ni amb cap dòna de la companyia; cal fer un reglament seriós, escullir el personal, donant amplies facultats al director per fer i desfer, sense tallar-li les ales».

Y, para concluir, citaremos un artículo de Lorenzo Aparicio, que apareció unos años antes, en 1904 en el número 4 del Boletín de la Sociedad El Teatro, bajo el título «Causas de la decadencia de nuestro teatro» —en castellano pero creemos que hace referencia a la escena catalana- donde, de forma general tenemos algunas de las causas de la crisis teatral, en el cual se critica a los autores, a los cómicos y al público. Del primero dice que «dejándose llevar más que de su amor á lo bello de un censurable materialismo, encuentran más cómodo el coger una obra extranjera, traducirla y darla á la escena, con lo que las más de las veces, presentan producciones que son verdaderos engendros, en que la moral y el buen gusto, condiciones precisas para que el arte brille en todo su esplendor y el teatro resulte un centro de cultura y enseñanza, rueden por el suelo». De los cómicos comenta que carecen de la cultura necesaria para el conocimiento de los diferentes personajes que les confían.

Tras esta introducción general al problema de la crisis del teatro catalán, pasaremos a enumeran las diferentes causas que se citan en la revista como elementos distorsionadores y provocadores de ésta. Citaremos seis criterios que según los redactores e integrantes del mundo teatral originan la crisis.

\section{a) Los empresarios}

Un factor de la crisis del teatro catalán es la organización y el modo de llevar las empresas. Ignasi Iglesias dice que «dur al teatre els mètodes administratius de la botiga és no saber què és lo pràctic ni què és l'art». Alexandre Plana en un artículo publicado en El Poble Català, «Sobre la crisi del Teatre Català» (27II-1911), comenta lo siguiente: «Les nostres empreses teatrals són sempre porugues, i tota activitat està renyida amb la por. Estrenen les obres amb por, gasten els diners amb recança per por i no se llencen de ple a la infinida varietat de l'anunci i del reclam, perquè tot lo que no sigui comptar per mitges pessetes els hi fa perdre el món de vista». ${ }^{32}$ También advierte que: «El problema del tea-

${ }^{31}$ Núm. 52 (22 de febrer de 1913), p. 122.

${ }^{32}$ Teoria i Crítica del Teatre, a cura de Iolanda Pelegrí, Barcelona, Publicacions de I'Institut del teatre, Edicions 62, 1976, p. 33 
tre català és, doncs, un problema d'empresa i un problema d'actors, problema de direcció i problema d'interpretació».33

A los empresarios se les critica como hemos visto más arriba su política empresarial, es decir, las ansias de ganar dinero con el teatro, como se refleja en un artículo de Vicenç Caldés Arús, Encara sobre la crisi del teatre català $3^{34}$ no observa que los verdaderos culpables de la crisis sean los empresarios, sino el negocio, además del cine, por su bajo coste en los precios, y el público. ${ }^{35}$

En el número 43 , en su Crònica, ${ }^{36}$ se critica la labor de los empresarios barceloneses por las escasas producciones interesantes; solamente se pueden destacar los empresarios del Teatre de les Novetats y del Espanyol, porque «han fet honrada labor artística, i s'han fet càrrec de que en l'escena tot es important, contribuint poderosament el decorat a donar relleu a les produccions dels nostres autors».

Conrad Roure en una entrevista con Ramon Vilaró i Guillemi ${ }^{37}$ comenta lo siguiente: «El teatre català està mancat d'un empresari, i aquest, tant li fa que sigui artista com no, però sí aquest home desitjat no surt, sería de llei que algú, o alguns, seguíssim l'exemple d'En Pitarra, que si és veritat sigué empressari, no ho fou pas per sa voluntat». ${ }^{38}$

\section{b) Los autores}

En cuanto a los autores, se les realizan pocas críticas. Solamente encontramos el siguiente en una de las Ironies de Puck, ${ }^{39}$ donde se les critica el cambio en la concepción de las obras, que antes se hacían pensando en los actores, ahora ya no.

En una conferencia de Ambrosi Carrión en el Foment del Teatre Català, ${ }^{40}$ «El moment actual del teatre català. Conceptes», se analiza el papel de diversos elementos que conforman el mundo del teatro, y de los autores consagrados comenta:

33 Op. cit., p. 34

${ }^{34}$ Núm. 93 (6 de desembre de 1913), pp. 846-848

35 Adrià Gual en su libro Les orientacions comenta lo siguiente de los empresarios: «Crec que resulta de tot punt irrisori donar a les empreses la més petita culpa de lo que passa en el nostre teatre. Amb una ignocents, públic d'una banda y autors y elements de teatre de l'altra, ataquen crudelment als empresaris, perquè fan del teatre arma de negoci, essent així que quasi sempre tots ells acceptan el comès de l'empresari com tracte comercial» (pp. 22-23).

36 Núm. 43 (21 de desembre de 1912), p. 1.

${ }_{37}$ Núm. 253 (6 de gener de 1917), pp. 7-8.

${ }^{38}$ También podemos citar otros ejemplos como la Crònica. L'Institució "El Teatre Català" L'empresari, núm. 92 (29 de novembre de 1913), pp. 825-826, el artículo de Aroma, Segueix la confusió, núm.129 (15 d'agost de 1914), pp. 534-535.

${ }^{39}$ Núm. 133 (13 de setembre de 1914), p. 596.

${ }^{40}$ Esta conferencia fue publicada en las páginas de nuestra revista en los números: 203 (pp. 3637), 204 (pp. 52-54), 205 (pp. 70-72), 206 (pp. 86-87) y 207 (pp.99-100) 
«...aquest mateixos que han sigut els qui en un temps han consolidat l'escena $\mathrm{i}$ després els qui l'han sostingut amb llur prestigi, esdevenen per raó natural una mena de contrapès que priva de pujar als qui volen arrivar fins ells. Un petit egoísme molt humà i natural personalment, en té la culpa; i quan ells inconscientment defensen el dret al seu lloc, vé la lluita i la desunió i el teatre ja trova un entorpiment en el seu camí. No cal dir perquè.

.... La dificultat és la lluita d'escoles. Quasi tot home que arriva al cim, es creu haver trovat la fòrmula definitiva, única; no una de tantes formes definitives, com hi ha en l'art i que son com aquest infinites"

\section{c) Los actores}

A los actores se les critican dos cosas: su formación y la emigración de estos a otros lugares para poder vivir de su trabajo.

En cuanto al primer punto, antes de pasar a nuestra revista, vamos a ver las críticas que realizó Federico Urrecha en una conferencia ofrecida en el Ateneo de Barcelona en 1910 , con el título «El teatro contemporáneo en Barcelona»: ${ }^{41}$

«Tenemos plétora de primeros actores. Yo sé decir que no conozco más que primeros actores y que nunca he sabido donde se meten los segundos y terceros, aunque debe de haberlos en alguna parte, porque decir primeros es principio de un orden de relación que exige que haya segundos, terceros, etc.» (p. 10)

«... á vosotros que no conocéis del teatro más que el plato servido y condimentado, os diré que el que veis sobre la mesa ha necesitado larga y laboriosa preparación, pero exceptuando contadas compañías es en el teatro nuestro aquella preparación una cosa fantástica. Este génesis de la obra teatral se llama estudio y ensayo, que debieran ser base y fundamento del negocio. Solamente los inspirados y los genios improvisan, y entre nuestros cómicos hay pocos inspirados y ningún genio, aunque haya algunos con mucho genio, que no es lo mismo... Un cómico concienzudo llega á estudiar su papel, pero generalmente le importan un rábano los de los demás. Suponiendo la existencia de una compañía toda ella de concienzudos, fenómeno que no ha existido nunca, nada harían sin ensayar lo que han aprendido, sin fundir aquellas partes en un todo homogéneo. Entre nosotros un ensayo se compone de una mesa con dos bujías, una silla delante de la mesa para el apuntador, y otras para los artistas. En los teatros que van boyantes hay, un brasero á la izquierda para los cómicos de primera fila... » (pp. 17-18)

En la conferencia arriba mencionada de Ambrosi Carrión se comenta que el defecto de los actores es: «un excés potser de condicions expressives i una manca de cultura. No tracto pas d'ofendre'ls, i entre ells hi han excepcions, però és la veritat. Moguts per una afició excessiva al seu art, s'hi han llençat desse-

${ }^{41}$ Publicada posteriormente por Tipografía «La Académia» de Serra Hnos. y Rossell, 1910. 
guida, sense preparació de cap mena, i d'això els primers que n'han sortit perjudicats son ells mateixos, per que ni s'han pogut seleccionar ni especificar. Avui dia contem amb una colla que serveixen per a tot discretament, i que perfectament no poden fer quasi rès». ${ }^{42}$

Marsyas en el artículo, Acotacions, ${ }^{43}$ diciendo que no tiene ninguna noción de Historia del Arte ni Historia del Teatro, comenta que son dos asignaturas que serían idóneas para completar su formación y llevar las obras en mejores condiciones a las tablas. También esta crítica apareció en un artículo del periódico La Publicidad, el cual comenta muchos de los defectos del actor catalán, que nuestra revista en ocasiones ha hecho constar en sus planas, como la falta de estudio de los papeles. ${ }^{44}$

En la Crònica. La disciplina ${ }^{45}$ se comenta cómo debe tener el actor esta virtud, siendo necesaria en el mundo del teatro: «virtut o condició molt poc avinenta a la nostre manera de ser». También J. Ferran Torres en el artículo Per la noblesa del nostre comediant ${ }^{46}$ pone de manifiesto que los artistas necesitan una disciplina y unos estudios para poder expresar mejor sus ideas artísticas, mientras que el actor, en la actualidad, no ha necesitado unos estudios para ejercer su profesión. Este pide que el actor inicie su andadura con unos estudios para ennoblecer el arte teatral. Por su parte, Raimond en su crónica semanal del teatro castellano del número $45,{ }^{47}$ califica al actor catalán de: «dur, aspre, degut a que la majoria de personatges que interpreta ho són»

Acorde con esos criterios, Narcís Oller en sus Memòries teatrals ${ }^{48}$ realiza una crítica a la forma de ensayar de los actores catalanes:

«Els nostres actors, ni dins ni fora del teatre, volen estudiar-se el paper: tot s'ho aprenen de boca de l'apuntador. Així els ensaigs poden més bé comparar-se a una lliçó de solfeig, a on esperarem en debades que aparegui el matís de la frase, el sentiment especial de cada situació i molt menys encara el del conjunt de l'obra. Allí se l'aprenen ells a força de repetir cada dia com cotorres les paraules que pesquen de l'apuntador, sens la menor entonació i ben de pressa, per a poder enllestir ben aviat la feina jornalera, com, per sa part, ho procura també el director, limitant-se a donar a cadascú d'ells les entrades i sortides, a agrupar-los indicant-los-hi quan han de seure o estar drets, quina entrada, quin mutis ha d'ésser natural, pensat o precipitat, i a fer-los-hi entendre que tal cadira de les ajagudes representa una taula i aquella un sofâ, un escalfapanxes o bé un llit. I així sol fer-se durant tots els ensaigs, que, per lo comú, se redueixen, quant més, a cinc o sis dels que en diuen de taula $\mathrm{i}$, últimament, a dos o tres de concha, perquè la cotorra, que ha après ja a pescar la lletra de prop,

42 Véase la nota 38.

${ }_{43}$ Núm. 32 (5 de setembre de 1914), p. 586.

44 Parte de este artículo fue publicado en el núm. 218 (29 de abril de 1916) pp. 156-157.

45 Núm. 69 (22 de maig de 1915), pp. 337-338.

46 Núm. 237 (9 de setembre de 1916), pp. 313-314.

47 Núm. 45 (4 de janer de 1912), pp. 11-12.

${ }^{48}$ Memòries teatrals, edición a cargo de Enric Gallén, Barcelona, La Magrana, 2001, pp. 67-68. 
avesi l'orella a sentir-la i pescar-la de lluny. Poc cal dir amb quin cor més petit no en sortrà cada dia d'aquests ensaigs cabalístics, el pobre autor o traductor novell!»

Otra crítica que se les hace - y este es el segundo punto - es la emigración del actor catalán a otras tierras, causada por las penurias económicas del teatro catalán, que paga escasos sueldos a los actores, debiendo irse a otros lugares, como Madrid, donde cobran una mayor cantidad de dinero. Un ejemplo de esta crítica es la de Ramon Vilaró i Guillemí, Els fills de Judes,${ }^{49}$ donde se critica a los cómicos por su actitud de abandono del teatro en catalán, pues se marchan fuera a realizar teatro en otras lenguas, incluso sin conocerlas. Pone el ejemplo de Grasso, y el teatro siciliano, pues este actor lleva el teatro siciliano a cualquier lugar donde se traslade. Los actores catalanes, por su parte, sólo realizan teatro por ganar dinero.

En la Crònica del número $58,{ }^{50}$ dedicada a la emigración de los artistas catalanes a otras tierras para triunfar, se advierte que estos artistas fracasan en su intento y deben volver, a excepción de Enric Borràs:

«...Es llògic que això passi, no perquè els nostres artistes de teatre siguin inferiors als altres països, sinó per propria naturalesa de les coses, per la manera especial com va a fer teatre.

La seva primera preocupació, al sortir de Catalunya, és la d'estrafer la seva personalitat, la d'anul-tarse, la d'esser lo menys català possible. I duen el seu funest propòsit fins al punt de dir mal i de blasmar tot lo de la seva Patria; sense parar esment que aquesta conducta els indisposa amb els compatricis i repugna als estranys.

Però com a pecat que porta en si mateix la venjança, no aconsegueixen llevarse en absolut el segell netament català que porten, malgrat ells, ni logren adaptar-se a una altra naturalesa, esdevenint aixís uns organismes híbrids que careixen forçosament d'expressió i d'ànima, perquè ni han sabut prescindir en tot de la seva, ni han encertat a emmatllevar-ne una d'estranya, i fins l'accent, desentonant sempre, els traeix i inutilitza els seus esforços.

Que vagin els nostres còmics a Madrid, a Amèrica, a totes les terres... però amb la seva personalitat, essent ells mateixos, i fins parlant en català, i triomfaràn, com han triomfat aquí $i$ a tot arreu els artistes de diversos països que'ns visiten i que'ns donen el seu teatre essent ells mateixos.»

Y como conclusión de las críticas a la emigración de los actores catalanes, vamos a insertar unas palabras de Alexandre Nolla, en una entrevista realizada por Puck, ${ }^{51}$ donde explica las causas que le llevaron a abandonar el teatro catalán:

49 Núm. 48 (25 de janer de 1913), pp. 62-63.

so Núm. 58 (5 d'abril de 1913), pp. 218-219.

${ }^{5}$ Els actors catalans a Madrid. Alexandre Nolla, véase entrada 685 del anexo Índice de autores, p. 34. 
«...Ni ingratitut ni menyspreu puc sentir per un teatre que adoro, perquè en ell m'he format, perquè an ell dec tot lo poc que soc i lo que valc, perquè en ell saborejat les dolçors dels primers triomfs..., perquè és català i perquè és nostre... Jo estimo el Teatre Català i m'enorgulleixo de la meva tradició calalanesca... i si de quelcom mo dolc... és d'haver-me vist obligat a separar-me'n...

-Obligat?

- La necessitat ens empeny fòra de casa..., és trist confessar-ho, però, parlant per mi precisament, puc dir-li que no vaig emigrar amb l'il-lusio de conquerir llorers, que tant alts són i tant plens de dificultats per a nosaltres... Tinc esposa i una filla que han de menjar del meu treball..., és prosàic, és vulgar, però, ara com ara, a Catalunya aquestes necessitats primordials no podía cobrir-les amb el sol esforç del meu treball...

-Per mal retribuit?...

—No, perquè no ho fou..., sinó per l'inestabilitat del càrrec... Qui li assegura a un actor tres mesos seguits de treball? I suposant que'ls hi assegurin i els paguin bé, digui' $m$ de què ha de menjar els nou mesos restans de l'any?...”

También habla de la diferencia entre el teatro catalán y el castellano:

«El nostre teatre és de fer... El teatre castellà és de dir... De manera que la dificultat més grossa a vèncer per a nosaltres és dominar el tempreament, posar sordina a la nostra fogositat, afinar les maneres, educar el gest i la veu un ritme gris, igual, sense relleus ni contrastos massa pronunciats... Apendre tot lo que de superficial té el teatre, car és més mirat aquí el detall d'asseure's correctament, de llevar-se els guants amb inteligencia i de posar-se la corbata segons les exigencies de la moda, que'l de matitzar un personatge amb tots els sotracs de les passions tal com un hom els senti...»

La última crítica que se realiza a los actores, se refiere a los actores aficionados; son pasivos en el teatro catalán, que no se deciden dar el salto a las tablas como ocurre en Francia o Italia, tal y como se comenta en la Crònica del número $25,{ }^{52}$ indicando los defectos:

«el de no decidir-se a adquirir majors coneixements en l'art o què's dediquen a perfeccionar els seus treballs fins a fer-los aptes pera esser desenrollats, amb aplaudiments i èxit, en les taules dels grans teatres»

«l'isolament en que viuen els aficionats; quasi tots ells se creuen haver assolit els cims de l'interpretació escènica adaptada al casino ont se mouen, i s'acontenten amb signar els programes amb el calificatiu de primer actor $\mathrm{i}$ director $\mathrm{i}$ amb les ressenyes laudatories dels periòdics professionals, tot $i$ malparlant del companys»

${ }^{92}$ Núm. 25 (17 d'agost de 1912), p. 2. 
A propósito de cuestiones de ese tipo, se comentaba en un artículo aparecido en La Veu de Catalunya ${ }^{53}$ aprovechando la apertura de la matrícula de la Escola Catalana d'Art Dramàtic, sobre la enseñanza y la formación del actor:

«... Perque el mal que pateixen sovint els nostres comediants-salvant excepcions tan honroses com escasses - és el d'haver-se'n improvisat sense la deguda preparació. Aixís pot citar-se d'un que ha arribat a vell fent comedies i va haver de preguntar un dia què volía dir el mot «epitalami»; aixís pot afirmar-se d'un altre que, d'una visita a Tarragona, ne retreia les muralles «enciclopèdiques»; i d'un tercer que, a l'embarcar-se per a Ciutadella de Menorca, manifestava molt seriós l'esperança de venir-ne carregat... de «pesos»; i d'un quart que no podía girar la llengua per a anomenar el «cronòmetre» com exigía el text de l'obra que representava; i d'un quint que, capficat amb la caracterització d'un personatge històric, deia molt formal:

- iAquests autors s'han arribat a pensar que els comediants hem de ser homes de carrera! -

Cosa a la qual no va haver-hi ningú que sabés replicar-li amb una afirmació rotunda i categòrica:

- iSi senyor que ho han de ser! -

Doncs ¿què? Homes de carrera i no altra cosa; homes de carrera que sàpiguen, no sols moure's amb desembres i parlar amb soltura, sinó per què's mouen i per què parles; homes de carrera que tinguin coneixements generals, que posseeixin una cultura literaria, que sàpiguen, sobre tot, l'historia del seu país i hagin adquirit en el seu coneixement aquella conciencia nacional que avui manca a la majoría»".

\section{d) El público: ${ }^{54}$}

Xenaro Mariñas del Valle, ${ }^{55}$ define de la siguiente forma el papel del público, dentro del teatro:

«Pódese facer literatura ou música ou pintura para o pobo; pero teatro, non, teatro ha de facerse co pobo, en estreita e cordial colaboración co pobo, recoñecido que o pobo non é outro que o público que está alí, non como simple curioso espectador alleo e desentendido do drama - que ha de encher o local enteiro e non únicamente os altos do tablado- está alí reunido, convocado

\$.3 «A propòsit de l'anunci de matricula a l'Escola», 20 de septiembre de 1913, Any XXIII, núm. 5160 , p. 1.

${ }_{44}$ Antonio Álamo, en su libro ¿Dónde está el público? (Murcia, Escuela Superior de Arte Dramático de Murcia, 1998), comenta lo siguiente sobre el público: «En el teatro,..., el factor "público» resulta determinante. El teatro necesita hasta tal punto del público que el dramaturgo debe hacer un enorme esfuerzo de objetivación, y es ésa precisamente la finalidad última de toda técnica dramática, que a fin de cuentas se basa en la lógica.» (p. 7)

55 Importancia do público na revelancia teatral: discurso lído o día 25 de febreiro de 1978, A Coruña, Ediciós do Castro, 1979, p. 26. 
para algo máis que decir amén e conceder un aplauso de gracia. Está alí para sentenciar, para decidir si aquelo que se lle apresenta é a interpretación fiel e estética do seu arcano mensaxe. Na asmbleia do espectáculo teatral o público ten voz e voto e ha de usalos libremente, pródigamente»

Ya en la época que tratamos, Josep Ixart también se preocupó del papel del público y su comportamiento en sus crónicas teatrales, como podemos ver en el siguiente artículo, «Estrenos. Los Estrenos», aparecido en su libro El año pasado $1886:^{56}$

«... cada vez que debuta alguna celebridad artística de las que vienen aquí de paso, siguiendo sus iargas excursiones por el mundo. Y lo que ocurre es: que el público exagerando sus alardes de independencia, lejos de respetar desde luego en el artista la gloria adquirida, sin perjuicio de discutirla más tarde, acude a verle con fría prevención, y no quiere comprometerse a saludarle hasta tanto que le ha oído muy despacio y con altanero silencio. Buena es la independencia de criterio; pero no a tal punto, señores. No parece sino que, entre todos los públicos del globo, forma el nuestro una especie de Tribunal Supremo, al que importan los fallos de los inferiores, los cuales revoca o confirma según le parece. Un aplauso siquiera a la salida, concedido si no al mérito a la fama, me parece que no estaría de más en muchos casos y no había de impedir que luego dijésemos libremente lo que nos pareciera, aunque se tratase del primer genio del universo»

Y continúa diciendo:

«... la sociedad, en una palabra, que va al teatro caro, sólo porque está caro, y va a contemplarse a sí misma, a lucir, a enseñar el escote; la sociedad, para la cual el acto de una comedia es el entreacto de silencio (cuando lo guarda), y el entreacto, el acto verdadero, durante el cual se abanica, galantea, ríe, entra, sale, se vuelve asesta los gemelos a derecha e izquierda y lo hace todo menos mostrar algún interés por la función: conjunto de figuras decorativas, siempre las mismas, que, mientras se representa o se canta, parece que están allí para que se vea que hay alguien en el teatro; multitud impaciente y como deseosa de acabar su papel, y ponerse a charlar; niña mimada, a quien le están contando cosas que no le importan, vestida de baile y mientras rabia por valsar en cuanto acaben». ${ }^{57}$

Así, ya en la publicación aquí estudiada, Manel Folch i Torres en su artículo Concepte previ ${ }^{58}$ comenta la importancia del público como regulador de la actividad teatral, pues puede exigir buenas obras a los empresarios y una mejor representación a los actores, como "armonitzador dels altres tres factors esmentats» ${ }^{59} \mathrm{y}$ «agent actiu en la manifestació artística».

${ }^{56}$ En Obra Completa de Josep Ixart. Volum I: El año pasado (1886-1888), Tarragona-BarceIona, Proa, 1995, pp. 107-108.

${ }^{57}$ Op. cit., p. 109

${ }^{58}$ Núm. 2 (7 de març de 1912), pp. 3-4.

${ }^{59}$ Se está refiriendo a empresarios, autores y actores. 
Una de las críticas que se vierte sobre el público del teatro catalán es el gusto por las obras tradicionales más que por las nuevas; esto lo podemos constatar en el número 35 en su Crònica: ${ }^{60}$

«... el teatre vol viure amb el temps, i admet, més que qualsevol altra institució artística, renovacions que l'emmenin en camí de progrés i el facin apte pera desempenyar l'altíssima acció social que realitza...». Dice que lo que no admite el público es el teatre d'idees. El teatro naturalista ha sido aceptado tras grandes discusiones, ya que rompió con la estética reinante hasta la fecha, las comedias de capa y espada...

Però això havía de cansar, no tant al públic com a l'èlite dels intelectuals del teatre, que com més refinen la seva sensibilitat estètica més s'aparten de l'art dramàtic, fins a quedar-ne del tot divorciats, malgrat ells; i d'aquí nasqué el drama d'idees i el verisme...

Aqueix teatre podía despertar curiositat, però mai admiració. Era antiestètic i immoral. Si algun cop adquiría grandesa era quan el geni de l'Ibsen l'animava, però pera esser ben aviat oblidat per tot el món. (...) però ja ho hem dit altres vegades: lo que l'escena necessita es que s'hi dugui la vida exuberant i eterna de les passions i dels ensomnis, mai una abstracció incompatible amb el sentit d'una multitut $i$ enemic del suau optimisme que es moral i estètica alhora infondre a les colectivitats.»

También en otra Crònica La santa continuitat ${ }^{61}$ se hace hincapié en esta idea que el público catalán está todavía anclado en el pasado.

Y por último vamos a indicar el concepto de público según dos actores catalanes, Joaquim Montero y Miquel Rojas. El primero, en Jo, parlar de mi? , ,2 califica de la siguiente forma al público que asiste a sus representaciones:

«Quan vaig desembarcar van dir-me'n coses tremendes d'aquest públic. Que no més se recrea en el cine, que era necessari implantar el teatre a les fosques, que ja no té cap mena d'afició a les comedies, que això està perdut, que pensa lo que fas, que mira-t'hi bé... Res, que quasi m'havien convençut d'anar a comprar el bitllet de regreso.

Sortosament, no tothom és pessimista com aquells que m'aconsellaven coses tant tristes, i no va faltar qui em va dir: - No t'espantis, Quimet. Deixa dir, que si la gent no va al teatre és perquè... i aquí va donar-me una pila de raons semblants a les que dóna el públic quan senta càtedra al primer quadre de ;Arriba el telón!

- Doncs provarem, - -vaig dir jo--- Vui assegurar-me'n d'aquest refredament del meu públic que tant he anyorat.»

\footnotetext{
6) Núm. 35 (26 d'octubre de 1912), pp. 2-3.

61 Núm. 105 (28 de febrer de 1914), pp. 146-147.

62 Núm. 84 (4 d'octubre de 1913), p. 694.
} 
El segundo, en una entrevista con Josep Ferrán Torras, ${ }^{63}$ comenta acerca del cansancio que provoca ser actor, sobre el público del melodrama y sobre el género. Define el público que asiste al teatro Apol de la siguiente manera:

«El públic era una massa d'homens i dónes, apretats els uns amb els altres, aguantant de peu dret, molts d'ells, tota la tarde, havent de respirar una atmòsfera espessa, aviciada, amb una calor asfixiant.

Aquest públic restava quiet, silenciós, pacient, absorvit per l'interès que li despertava lo que en la escena hi havía. Quan en ella feia l'aparició un determinat personatge; quan l'actor adoptava una actitut significativa; quan una frasse eixía virulenta o agressiva, tant sols aleshores s'aixecava, fins dels més obscurs indrets de la sala, un remoreig imposant com d'oleatge bramador»

\section{e) El cine}

Desde los primeros números de nuestra revista aparece la polémica del cine y el teatro, como uno de los causantes de la crisis teatral. Por ejemplo en el número 8 en su Crònica,${ }^{64}$ Curet comenta que el cine triunfa por su comodidad y su «baratura». ${ }^{65} \mathrm{Y}$ escribe lo siguiente:

«Es que'ls cinematògrafs se multipliquen i els teatres se decandeixen, i, a menys de no comptar amb subvencions o amb medis pera resistir l'indiferencia del públic, s'han de veure obligats a tancar les seves portes, després de campanyes ruinoses en les quals s'ha defensat l'entrada amb totes les combinacions i equilibris que l'instint de conservació fa imaginar»

Ambrosi Carrión en Del nostre teatre i per al nostre teatre ${ }^{66}$ acusa al cine como uno de los causantes de la crisis.

63 Núm. 174 (26 de juny de 1915), pp. 422-424.

${ }^{64}$ Núm. 8 (20 d'abril d 1912), pp. 2-3.

6.5 Adrià Gual expresa la misma idea en su libro Les orientacions. Estudi d'actualitat teatral catalana (Barcelona, Imprenta-Edicions Artís \& CO., 1911): «També es curiosa l'apreciació de la preponderancia cinematogràfica, y ho es tant més, per quant Barcelona es un dels llocs del món on major acceptació té l'espectacle de la projecció. Per què? Barcelona's caracterisa per una marcada tendencia a lo barato: mireu, si no, l'èxit de les liquidacions y les parodies de liquidacions. Mentres a Madrid y París (per no citar altres llocs) l'implantació de sales cinematogràfiques ha degenerat en petits cenacles escènics, convertint-se en llocs de representació teatral molts dels destinats a cine, a Barcelona bona part de teatres han sentat plassa de tals, amb la major acceptació del públic. Serà a causa del preu? Se fa dubtós creure-ho....

La condemnació del cine en contra del Teatre demostra una vegada més que aquells que la profereixen no han sabut mai què cosa era Teatre. Del moment que no poden establir la diferencia marcadíssima que existeix entre ambdós espectacles, se pot dir clarament que no han experimentat mai el goig del Teatre. Quí, anant al cine, se creu substituir l'emoció Teatre, no han sentit mai tal emoció y en el teatre hi ha trobat tant sols un element de bellugadissa externa» (pp. 25-26).

66 Núm. 70 (28 de septiembre de 1913), pp. 419-420. 
«I no és el cine, art més inferior encara, parodia ridícula del teatre? No us figureu el cine com una gran orquestra d'instruments tots muts, que per més que'ls músics bufin, piquin i esgarrapin, no dóna cap sò, i sols veiem els gestes dels executants i el mestre, més no arriba a nosaltres res de la veu armònica que'ns insinúen llurs moviments i frisances?

I no és l'art del teatre, el més excels per la seva esencia mateixa? No és tot ell la potença de la divina paraula formada acció i sentiment, força i armonía? Aixís com hi ha qui diu que totes les arts es troben en embrió, cal recordar que en el teatre totes s'agermanen i es completen"

Federico Urrecha en la conferencia anteriormente mencionada, comenta lo siguiente del cine: «Para luchar con alguna ventaja contra el cinematógrafo ha tenido el teatro que bajar sus precios, encontrándose entre la espada y la pared ante la necesidad de abaratarse sin dejar de pagar sueldos cada vez más crecidos».67

Pero entre estas críticas, tenemos una serie de artículos de Magí Muriáco donde se comenta la relación del teatro y del cine, intentando presentar el teatro y el cine como dos artes complementarios, que deben ayudarse para seguir hacia delante, pues cualquier obra teatral puede ser llevada al cine. Y en el artículo del número 237 se centra en los actores y critica a los actores catalanes por sus defectos a la hora de realizar cine o teatro. Los defectos que apunta son: la falta de elegancia y que «tots els nostres actors de primer rengle tenen un rei al còs».

\section{f) Los críticos}

En cuanto a las críticas contra las firmas que se encargan de las reseñas teatrales, desde las páginas de El Teatre Català se piensa que, como ya se dejó entrever en la Crònica publicada en el primer número, no hay que abusar de los elogios.

Existen varios artículos donde se da la visión de cómo debe ser un crítico y cómo tiene que realizar su trabajo. Un de estos pareceres se recoge en la Crònica del número 44 (28 de diciembre de 1912), donde Curet habla de la forma de hacer crítica literaria, debiendo conservarse la ética en la misma:

«Una veritable crítica, dotada de tots els prestigis pera considerar-la i fer-ne cas, es la que a l'analitzar defineix, la que, al judicar, aconsella i la que, en re-

${ }^{67}$ El teatro contemporáneo en Barcelona: conferencia dada en el Ateneo barcelonés el 22 de marzo de 1910, Barcelona, Tipografía «La Académica», de Serra Hnos. y Russell, 1910, p. 8

${ }_{68}$ Los artículos a que nos referimos son: «De l'ennobliment del cinematograf $i$ la seva relació amb el teatre i la literatura», número 233 (12 de agosto de 1916), pp. 281-282; «De l'ennobliment del cinematograf i la seva relació amb el teatre i la literatura (II) El teatre», número 234 ( 19 de agosto de 1916), p. 291; «De l'ennobliment del cinematograf i la seva relació amb el teatre i la literatura (III) La literatura. L'art en les diverses manifestacions», número 235 (26 de agosto de 1916), p. 291; y «De l'ennobliment del cinematograf i la seva relació amb el teatre i la literatura (IV) Els actors», número 237 ( 9 de septiembre de 1916), p. 315. 
sum, ens ensenya quelcom de nou, transmet a les vinentes generacions judicis precisos que, al mateix temps que posen les bases de l'historia literaria, donen més relleu a les obres objecte de la crítica i aclareixen punts que podríen semblar foscos.»

Otro ejemplo sería el artículo de Marsyas, Impressions de teatre (III). De la crític $a{ }^{69}$ artículo dedicado al crítico y cómo debe de ser. El crítico debe tener las siguientes condiciones: «no escrigui pas comedies i drames, car mal no sàpiga escriure-les, bé pot tenir el criteri necessari per judicar-les». Debe tener «una major cultura de la que posseeixen els nostres (fent escepció d'uns pocs), i així, al judicar les obres, no incorreràn en equivocacions, més pernicioses quan a voltes poden fer tòrcer el criteri del public, que en ells es fia per formar opinió sobre l'obra representada, allunyant-se del teatre i fent el buid a l'entorn de produccions que, tractades com mereixíen, hauríen assolit l'èxit degut i la popularitat merescuda». Y tiene que ser imparcial «en el sentit més ampli de la paraula.»

Vamos a finalizar con las sensaciones de Maria Morera expresadas en una entrevista realizada por Puck, ${ }^{70}$ donde la artista catalana se expresaba en los siguientes términos sobre la crítica de Madrid y de Barcelona; en la primera dice, son más «afalagadors, saben apreciar el treball d'un artista i no els dolen els elogis. Així com a Barcelona sols escriuen quan poden malparlar, aquí és tot al revés...».

Y en la conferencia ya mencionada de Ambrosi Carrión, éste comenta lo siguiente a cerca de los críticos:

«O millor dit les resenyes, que parlen de teatre ací, perque de crítica veritable no n'hi ha, han fet tot lo que han pogut per a ajudar a caure l'escena nacional.... Són generalment, o aspirants a autor que han fracassat, ans d'arrivar-hi, o gazetillers de 12 duros al mes, que per benevolença d'un director, o per que n'hi havía cap més a mà, fan les resenyes dels espectacles»

«Direu al escoltar tot això que entre nosaltres no hi han crítics? Veritablement no hi són! Crítics fonamentals com l'Yxart, no n'han sortit en nostra terra. Bé és veritat que n'hi han uns pocs moguts d'una bona fe, més no n'hi ha prou. Caldría per a fer la llur tasca tal com ha d'ésser, que el seu nivell fos superior o igual al dels qui judiquen. I amb això els millors no passen de ser uns senzills aficionats, i d'això al snob no hi ha més diferencia que unes lletres.

Després ací, predomina sobre tot la qüestió política o la capelleta. Quasi tots els autors, mirant no la seva obra, sinó el grau d'amistat en que's troben amb aquests senyors, poden dir per endavant qui judici els mereixerà. $« S i$ aquest és dels meus és bo, si és de la botiga del davant, dolent, per bé que ho faci.» Si a més de tot això hi intervé la política no cal parlar-ne.

69 Núm. 61 (26 d'abril de 1913), p. 274.

${ }^{70}$ Els actors catalans a Madrid. María Morera, número 67 (7 de septiembre de 1913), pp. 373-375. 
I encara n'hi ha una mena pitjor, Els d'aquests diaris que depenen de Madrid, i que'ns envíen uns quants senyors que enllà no serveixen per a rès, per treurese'ls del damunt i dona'ls-hi un sou»

\section{g) Otras causas: traducciones, toros, etc.}

También podemos destacar otras causas de la crisis que son apuntadas en la publicación estudiada, como son las traducciones, los toros, el exceso de producción y algunos géneros teatrales menores. La crítica a las traducciones insiste como problema en la traducción de obras teatrales que realmente no tienen valor artístico y no aportan nada nuevo al teatro. ${ }^{71}$ T. Ferrás en un artículo, De col.laboració. Plagues de teatre. Els traductors ${ }^{72}$ explica con una historia como «neix la personalitat artística del traductor». Acusa a los traductores como uno de los males del teatro catalán, no por el hecho de la traducción en sí, sino por como se hace la traducción.

Otra causa aludida es el mundo de los toros. En el número 70, en su Cròni$c a^{73}$ se comenta el aumento de la afición en Barcelona por los toros, aunque al redactor no le gusta este espectáculo; y en la del número 160 (Crònica. La plaça Monumental),${ }^{74}$ se comenta que muchos artículos críticos insisten en las corridas de taurinas como mal.

El tema del exceso de producción, no ha sido muy criticada dentro de nuestra publicación. Sólo disponemos de un ejemplo que aparece en el número 47, en su Crònica ${ }^{75}$ donde se alude a la producción masiva de obras que no han sido maduradas en su versión final, dando obras mal estructuradas y con grandes fallos, a modo de «desenfrenada furia d'escriure música de qualsevol manera... Que a tot això ha arribat l'afany de produir depressa i a preu fet, sense preocupar-se de la consistencia de lo que's fa ni pensar en si aquells afanys poden arribar a l'immortalitat».

Pero ya Josep Ixart, en su obra El año pasado $1887^{76}$ comentaba lo siguiente sobre este asunto:

«En el balance del año cómico de 1885 a 1886 publicado por la Revista Contemporánea, hallo algunos datos irrefutables que demuestran perfectamente adónde llega actualmente la decadencia de nuestra escena. Primer dato: con aumentarse prodigiosamente cada año el número de los estrenos, apenas queda luego de caudal una sola obra. ¡173 fueron las nuevas! ¿cuáles recuerda el público? Segundo dato: de las 49 que le corresponden en la anterior cifra a los teatros de primero y segundo orden, ¿quiere saber el lector cuántas son simples

${ }^{71}$ Núm. 4 (21 de març de 1912), p.2.

72 Núm. 88 (1 de novembre de 1913), pp. 756-757.

${ }^{73}$ Núm. 70 (28 de juny de 1913), pp. 417-418.

${ }^{74}$ Núm. 160 (20 de març de 1915), pp. 193-194.

${ }^{75}$ Núm. 47 (18 de janer de 1913), 34-35.

${ }^{76}$ Op. cit., p. 355. 
traducciones o arreglos? 29; más de una mitad: 29, según las declaraciones oficiales de los interesados, porque ahora vaya usted a saber (sobre todo tratándose de piececillas para los teatros por horas) cuántas se venden por originales sin serlo. Que punto a la paternidad de las comedias lo mejor es tener mucha fe y sentar sin más averiguaciones, como la ley, tratándose de otra paternidad también misteriosa: «his pater est quem nupcias, ect.» o sea: «quien figura en el cartel, éste es el padre» No tenerse aquí sería lanzarse a las tinieblas del escepticismo más desgarrador, dado el inmenso e ignorado fondo común de dramas, de donde pueden sustraerse argumentos sin que el más erudito lo perciba»

Y por último, cabe la crítica a los géneros teatrales menores, en especial sobre el vaudeville,$^{77}$ género importado del teatro francés, que en un principio fue perjudicial para el teatro catalán, pero que, en opinión del redactor, ya no cree que lo sea - «no pot causar-li mal de mort a l'art dramàtic català»-, aunque es un género que no le agrada nada:

«Ja hem dit que lo fonamentalment immoral del vodevil és trobar motiu de gracia en l'adulteri, els triomfs de les cortesanes i les burles gens edificants ni respectuoses entre pares i fills, marits i mullers... Admès això, i caldrà admetre-ho, ja que una corrent ens hi porta, i sinó fiquem-nos a un convent a fer penitencia, és preferible el vodevil, aont l'humorisme i la llei del xisto, tot portat d'una manera inverossímil i convencional, no deixa pòsit ni sediment en l'ànim de l'espectador, essent, al contrari, més perjudicial el genre seriós, també modern, també francès, també europeu, en el que's desenrotllen conflictes i situacions dramàtiques basades en el mateix esperit d'aquest teatre, perquè quan la seriositat del dramaturg vol donar caràcter d'apostolat o de crítica raonada o d'exemplar comentari a les seves produccions, exerceix una influencia educadora si construeix implacablement. I el vodevil, quan menys, és la part satírica, superficial d'aquest aspecte literari, fonamentalment malsà, i per això no causa, en general, altra preocupació immediata que fer riure i acostumar als espectadors a no avergonyir-se per coses groixudes que sentin.

El vodevil és immoral, no obstant? Per son fons? No és l'única manifestació literaria que hi peca. Per la forma? Conseguim que no sigui grollera i haurem avençat molt. No's coneixíen encara els vodevils, i la blasfemia inculta, el mot desvergonyit i l'obscenitat atentadora al bon gust $i$ als sentits, deshonraven la llengua catalana amb un caràcter tant genuí, que més aviat sembla un càstig sobrenatural que no pas un vici incivil.»

\section{Colofón}

A manera de cierre del presente artículo nos haremos eco de diferentes noticias aparecidas en la prensa en castellano sobre las diversas causas que llevan también al teatro castellano a la consabida crisis, demostrando que no era una preocupación exclusiva en la crítica teatral catalana.

${ }^{77}$ Véase Crònica. La moda del «vaudeville», núm. 116 (16 de maig de 1914), pp. 322-323. 
Las otras referencias encontradas en mis pesquisas son posteriores a las que presentan en la revista aquí utilizada, es decir, corresponden en su mayoría a los años veinte del siglo anterior. Pero son tan válidas como las otras, porque nos presentan una misma realidad, la preocupación por el teatro y todo aquello que lo rodea. Como veremos ahora, la mayoría de las acusaciones coinciden con las aparecidas en El Teatre Català, y se centran en los mismos elementos distorsionadores.

A los empresarios se les critica su política de precios y de gastos; estos se quejaban de los gastos tan altos que tenían, ${ }^{78}$ que les hacía mantener los precios por encima de los del cine y admitir sólo comedias de autores bien conocidos. Y se les acusaba de haber convertido el teatro en «un ambiente dramático de mercantilismo trapalón». ${ }^{79}$

A los autores se les criticaba otras causas, ya que, las dos literaturas se encontraban en dos dimensiones diferentes, la catalana en su resurgimiento y auge, y la castellana intentando mantener su cuota de mercado. Se les criticaba el «teatro simplista, de ñoñas sensiblerías pueriles o de absurdas peripecias grotescas ${ }^{80}$ y la industrialización de la escena. ${ }^{81}$

A los actores encontramos críticas parecidas como recoge Dougherty en el artículo «Talia convulsa: la crisis teatral de los años 20»: «su tendencia a buscar el aplauso a costa del arte de su oficio, su falta de preparación profesional y, sobre todo, su resistencia a aceptar el criterio del conjunto escénico, o sea, de integrarse en la compañía en vez de lucirse sobre los demás», ${ }^{82}$ siendo más explícito Gustavo Abril en La Noche de Barcelona: «El teatro no es sólo el actor, y una compañía no es únicamente la primera figura. En el teatro, y mucho más en el teatro moderno, todo tiene tanta importancia como el trabajo del «divo». El conjunto, la escena, la luz, los detalles plásticos y los efectos escénicos. Y, sobre todo, el «Teatro», es decir, la obra». ${ }^{83}$

En el teatro castellano, Ramón M. del Valle-Inclán en La Esfera (6 de marzo de 1915) acusa al público como el mayor acusante de la crisis su «mal gusto» y a continuación dice: «Fíjese usted que digo el mal gusto y no la incultura. Un público inculto tiene la posibilidad de educarse, y ésa es la misión del artista. Pero un público corrompido con el melodrama y la comedia ñoña es cosa perdida». Y Jacinto Benavente habla a Fernando Barango-Solís sobre el público en El Imparcial, comenta lo siguiente: «Aquí las cuestiones religiosas no se pueden tocar; en amor, no es posible salirse del matrimonio que se pelea y que luego hace las paces; de política no hay manera de hablar, porque todo el mundo se

78 Véase el Heraldo de Madrid del 28 de marzo de 19125, donde José del Río del Val hace un desglose de los gastos que tenía cada vez que se levantaba el telón en el teatro Martín.

${ }^{79}$ Enrique de Mesa en Apostillas a la escena, Madrid, Renacimiento, 1929, pp. 29 y 252

" José Romero Cuesta, «La crisis actual» en Heraldo de Madrid, 11 de abril de 1925

${ }^{81}$ Por ejemplo Ricardo Baeza en El Sol, 15 de diciembre de 1926 o Jacinto Grau en La Gaceta Literaria, núm. 5, 1 de marzo de 1927, p. 5.

${ }_{82}$ «Talia convulsa: la crisis teatral de los años 20" en Dos ensayos sobre teatro español de los veinte, Murcia, Universidad, 1984, p. 131.

${ }^{83}$ La Noche, 1 de junio de 1927 , p. 3 
disgusta, y en profundidades filosóficas no se meta usted porque no llegan a la gente. ;A ver cómo es posible hacer así teatro nuevo!» ${ }^{84}$

En los años veinte, en el mundo teatral castellano, era patente la rivalidad entre las dos artes, según los artículos aparecidos en la época. Algunos críticos pensaban que, con la irrupción del cine, el teatro evolucionaría hacia lo espectacular, como indicaron Azorín o Unamuno, que aluden a la renovación de la escena, a la supeditación de la palabra a los recursos visuales, es decir, a sustituir la declamación por la intensidad espectacular, como deja constancia Azorín en un artículo publicado en el $A B C$ el 1 de septiembre de 1927. Unamuno, por el contrario, mantenía que el teatro saldría ganando de la batalla con el cine precisamente porque no podía competir plásticamente con él. Al verse eclipsado como espectáculo, el teatro, para sobrevivir, tendría que volver «a su primitiva severidad de desnudez clásica y dejando para el cine todo lo que es ornamentación escénica». ${ }^{85}$

Y en cuanto a los críticos, M. Alcántara Gusart en un artículo aparecido en La Noche: «Las voces más contradictorias oídas en esta polémica son, sin duda alguna, aquellas que comentaban el papel de la crítica en la crisis teatral. Para los más, los críticos no hacían sino desorientar al público, contribuyendo así a su desgana respecto del teatro. Los jueces de los estrenos ofuscan - se decía- o por exceso de benevolencia, o bien, por mantener un criterio exageradamente severo" o como se refleja en un artículo de Azorín donde califica a los críticos de «falta de cultura e ignorancia de valores artísticos». ${ }^{86}$

${ }^{84}$ El Imperial, 3 de mayo de 1928, p. 3

${ }^{85}$ España, núm. 155, 28 de marzo de 1918, p. 12

${ }^{86}$ La Noche, 17 de junio de 1926. 